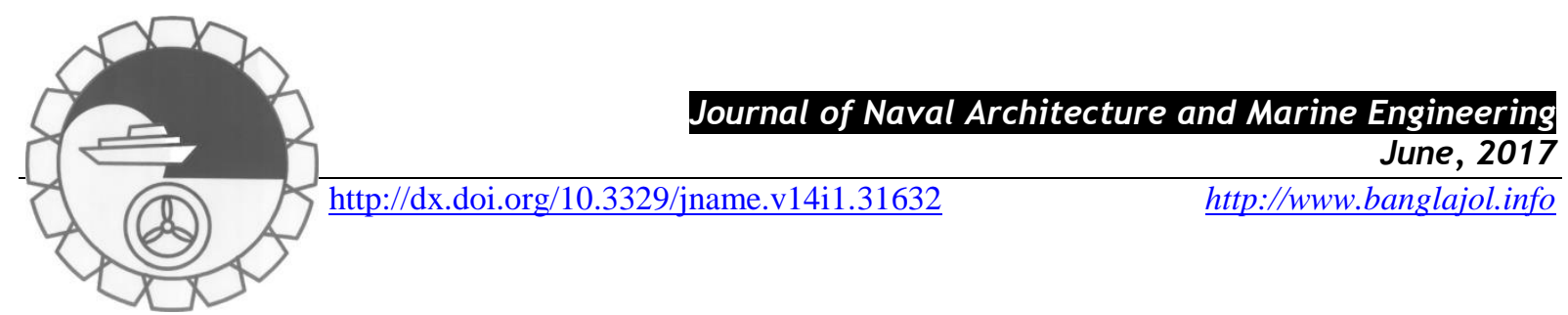

\title{
THE EFFECT OF ELECTRICAL DISCHARGE MACHINING PARAMETERS ON ALLOY DIN 1.2080 USING THE TAGUCHI METHOD AND DETERMINANT OF OPTIMAL DESIGN OF EXPERIMENTS
}

\author{
Pouyan Sadr ${ }^{1}$, Amin Kolahdooz ${ }^{2} *$, Seyyed Ali Eftekhari ${ }^{3}$ \\ ${ }^{1}$ Department of Mechanical Engineering, Khomeinishahr Branch, Islamic Azad University, Khomeinishahr/Isfahan, Iran. \\ ${ }^{2}$ Young Researchers and Elite Club, Khomeinishahr Branch, Islamic Azad University, Isfahan, Iran. (Corresponding Author) \\ ${ }^{3}$ Young Researchers and Elite Club, Khomeinishahr Branch, Islamic Azad University, Khomeinishahr/Isfahan, Iran. \\ Email: ${ }^{1}$ pouyansadr@iaukhsh.ac.ir, ${ }^{2}$ aminkolahdooz@iaukhsh.ac.ir, aminkolahdooz@ gmail.com, ${ }^{3}$ a.eftekhari@iaukhsh.ac.ir.
}

\begin{abstract}
:
Electrical Discharge Machining (EDM) process is one of the most widely used methods for machining. This method is used to form parts that conduct electricity. This method of machining has used for hard materials and therefore select the correct values of parameters are so effective on the quality machining of parts. D3 steel has a high abrasion resistance at low temperatures therefore can be a good candidate for this method of machining. Also because of high hardness and low distortion during heat treatment, using this method is economical for this alloy. The purpose of this paper is to investigate the influence of the main parameters such as voltage, current, pulse duration and pulse off time and the interaction of them to determine the optimal condition for the D3 steel alloy (alloy with DIN 1.2080). Chip removal rate (MRR) and surface quality of parts were evaluated as the output characteristic of the study. The optimum conditions were achieved when the MRR is in the highest value and surface roughness is in the lowest one. For investigation of interaction, two kinds of DOE methods (Taguchi and determinant of optimal experimental design) are used. Then the optimal parameters are investigated with the help of the analysis signal to noise $(S / N)$ and mathematical modeling. The optimize results were tested again and compared. Also the results showed that regression modeling has better accuracy than the $S / N$ analysis. This is because of a greater number of experiments that done in this part and taking into account the interaction parameters in the regression model.
\end{abstract}

Keywords: Electrical discharge machining, D3 steel, Taguchi, D-optimal, regression modeling, optimization.

\section{Introduction}

EDM process, that is a subset of thermo-electric machining, is used as non-conventional machining method for machining metals and conductive materials. In this method, successive electrical sparks take place between the electrode and the workpiece in a dielectric fluid medium. As in EDM electric-heating energy is used instead of mechanical shear forces, it can be used for machining cut resistant materials such as hardened steel, tungsten carbide and alloys with high strength as well as complex shapes. Moreover, in this method, owing to the absence of mechanical force, the machining of fragile parts is possible presented by Kalpakjian (1995), Semiromi and Azimian (2011) and Zarringhalam et al. (2016). Because of having several effective parameters, EDM process is considered as one of the multivariate processes. Therefore, the conducted studies in the field of EDM have been mainly focused on the change and control of optimal adjustment of machining parameters with regard to the type of workpiece. The researchers also have mainly focused on the use of statistical methods and particularly, design of experiment (DOE) studied by Nourouzi et al. (2012), Hashemzadeh et al. (2017), Esfe et al. (2016) and Jafari Dinani (2016). The use of DOE method in order to optimize electrical discharge machining parameters for MAR-M274 alloy (nickel-based) has been investigated by Uhlmann et al. (2013). They have been shown that the pulse current and pulse on time are the most influential parameters for this alloy. Additionally, their results showed that the increased voltage leads to increased gap and therefore MRR will be increased. Ayestaa et al. (2013) have investigated the effects of current, voltage and pulse on-time for C1023 alloy using the Taguchi method and analysis of variance. It has been shown that the increased current intensity and pulse on time will reduce tool wear rate. Moreover, the lower current and voltage will be decrease the MRR. Gopakalannan et al. (2012) have investigated the effect of electrical discharge machining parameters on MRR, tool wear rate, and surface roughness. In this paper, they have shown that the current intensity and pulse on time 1813-8235 (Print), 2070-8998 (Online) @ 2017 ANAME Publication. All rights reserved. $\quad$ Received on: February, 2017 
have the greatest impact on outputs. Also they have shown that with increasing current intensity, at first MRR will be increased and then decreased. Furthermore, with increasing current intensity and also pulse on time, surface quality will increase. Clijsters (2010) investigated MRR and surface quality for the SiC ceramic machining. He chose the current intensity, voltage, pulse on time, and pulse off time as the input parameters for his work. He showed that the high energy leads to the instability of machining. In addition, for rough MRR, current intensity and pulse on time should be high. Tzeng (2008) has optimized electrical discharge machining process for SKD11 tool steels. His experiments showed that current intensity, work parameter and pulse on time have the highest impact on unloading rate and surface roughness respectively. Rajmohan and Prubho (2012) considering the parameters of voltage, current intensity, and pulse on time and off time, have tried to optimize MRR in 304 stainless steel. They suggested that the current intensity and pulse off time have the strongest impact on MRR of the 304 stainless steel. Moreover, for having the highest MRR, optimal setting levels have been calculated using $\mathrm{S} / \mathrm{N}$ ratio. They showed that despite the small number of experiments in the Taguchi method, this method provides acceptable results. Zarepour et al. (2007) using the Taguchi method, have investigated the wear of copper tool in EDM of DIN 1.2714 tool steel. They found out that current intensity has the greatest impact on tool wear rate. Additionally, they determined the optimal levels of the parameters using the method of S/N ratio. Tzeng and Chen (2007) used a Taguchi fuzzy-based approach in order to optimize high-speed electrical discharge machining of SKD11 tool steel. In this research, it was observed that pulse on time, work parameter, and current intensity has the greatest impact on the accuracy and precision of the process respectively. Moreover, it was found that the amount of particles added to the dielectric have no notable impact on the quality. Optimization of machining parameters for machining in micro EDM for Inconel 718 super alloys was investigated by Manikandan and Venkatesan (2012). The Taguchi method was used to formulate the experiment layout. The experimental results show that current and pulse on-time have a significant effect on machining characteristics. Experimental investigation was carried out based on Taguchi experimental design to study the effect of orbital parameters during electro discharge machining of nickel by Dave et al. (2012). They used $\mathrm{S} / \mathrm{N}$ analysis and ANOVA to identify the significant parameters and their degree of contribution in the process output. The results reveal that pulse on-time has significant influence on the machining characteristics studied by Yazdi et al. (2016) and Mirkalantari et al. (2017). The influence of input parameters on the MRR was studied by Vishwakarma et al. (2012). Mathematical model to formulate the input parameters like current, voltage, pulse on-time and flushing pressure to MRR of EN-19 alloy steel was developed in their research. They found that the most significant EDM parameters is the pulse current followed by pulse on-time and voltage. Literature review shows that little research has been conducted on EDM of specific material, especially coldwork tool steel. Since the effect of setting parameters and determining their optimal level depends on both the kind of workpiece and machining conditions, practical experiments should be done again for each alloy and specific material. Despite the increasing use of DIN 1.2080 alloy, particularly in Iran, no research has been conducted for the improvement of its EDM conditions, the performance of different methods of modeling, and calculation of the optimized condition.

In general, the objectives of this research can be summarized as follows:

1. Obtaining experimental data of EDM process for D3 alloy using two kinds of DOE Method.

2. Recognition and creation of a significant relationship between the process input parameters and important output characteristics such as MRR and surface roughness through providing regression models.

3. Identification of the interaction parameters and the effect of these parameters on the process output characteristics.

4. Estimation of the output values based on the determined input for optimization.

5. Providing two efficient optimization methods for the determination of the optimal levels of setting parameters in order to achieve optimal output characteristics in the process.

\section{Experimental Procedure}

\subsection{Work material}

Cold work Tool Steel 1.2080 (DIN X210Cr12, AISI D3) was selected as work material to carry out the experiment. D3 is an air hardening tool steel with have high carbon and high chromium. It displays excellent the abrasion and wear resistance. This alloy is heat treatable and will offer the hardness in the rage of 58-64 HRC. It is used in manufacturing of blanking tools, thread rolling dies, drawing dies and pressing tools for the ceramics and cold rolls for multiple roller strands Vishwakarma et al. (2012) and Kolahdooz et al. (2014). 
Table 1: Chemical composition of AISI D3

\begin{tabular}{ccccccc}
\hline $\mathrm{Cr}$ & $\mathrm{S}$ & $\mathrm{P}$ & $\mathrm{Mn}$ & $\mathrm{Si}$ & $\mathrm{C}$ & Element \\
\hline 11.00 & $\ldots$ & $\ldots$ & 0.206 & 0.10 & 1.90 & $\%$ Min \\
\hline 13.00 & 0.030 & 0.030 & 0.60 & 0.60 & 2.20 & $\%$ Max \\
\hline
\end{tabular}

The tool electrode was selected the copper with $99.9 \%$ purity and $40 \mathrm{~mm}$ diameter. For easier installment of electrode in tool holder, a tail was considered with length of $100 \mathrm{~mm}$ and diameter of $11 \mathrm{~mm}$. With using a hacksaw machine, the samples were cut from a $7 \mathrm{~mm}$ diameter cylindrical profile exactly and with similar thickness. Then, the surface of the samples was polished using a milling machine and grinding. Also, both sides of the samples were coded for a more precise control and tracking before doing experiments. Figure 1 shows one of the samples and the electrode used in this research.

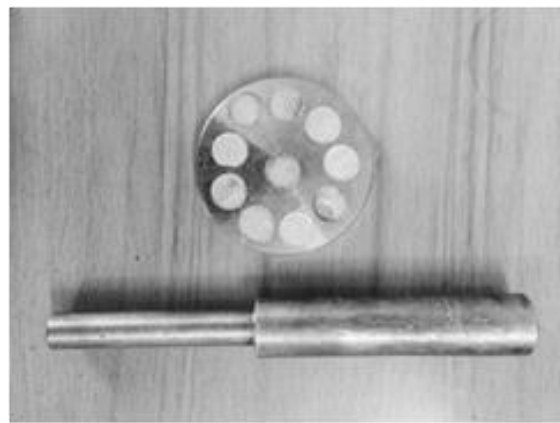

Figure 1: A view of the sample and electrode used in the research

\subsection{The equipment}

Die-sinking machine, model 50A-501, was used in order to carry out for the designed experiments (See Figure 2). Among the most important features of this machine the following may be mentioned: the ability to change most of the setting parameters, high precision, and efficient cleaning/washing system. The washing system of this machine is dipping and spraying type. Therefore during the machining process, the workpiece is completely immersed in dielectric fluid (ordinary oil) and a spraying flow helps for better washing. Surface roughness of the machined samples was measured based on Ra criteria and with 0.01 precision through using made in Germany MEHR MARSURF roughness tester model M300C. In order to reduce errors in determining the numerical values of the surface roughness, the prop was moved about $5 \mathrm{~mm}$ on the surface of the sample and in several different directions. To measure MRR, the mass of sample was compared before and after machining. FEJ200 digital scale, manufactured in FEW Company in China, was used which has the precision of 0.01 gr.

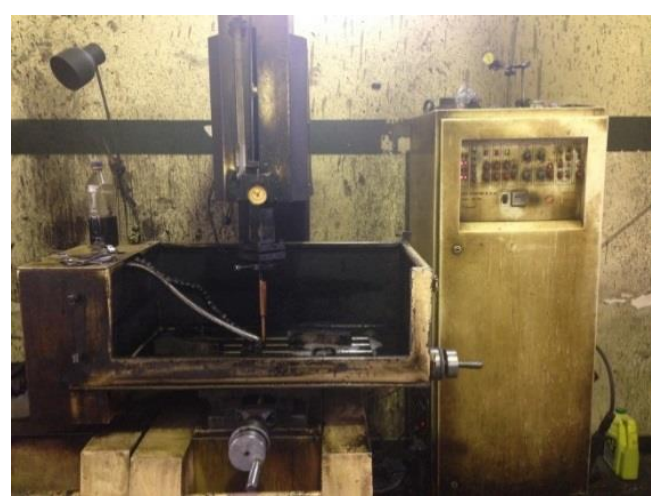

Figure 2: Die-sinking machine, model 50A-501

\subsection{Design of experiment}

In this research, the effect of four parameters of voltage, current intensity, pulse on time, and pulse off time among the existing inputs on two output parameters of MRR and surface roughness has been investigated. The parameters and levels were determined according to Table 2. These levels were selected according to the electrode diameter and upper and lower limits of the used machine. 
Table 2: Process parameters and their levels

\begin{tabular}{ccccc}
\hline \multicolumn{3}{c}{ levels } & & \\
\cline { 1 - 3 } 3 & 2 & 1 & Unit & Parameter \\
\cline { 1 - 2 } 20 & 220 & 100 & $\mathrm{~V}$ & Gap Voltage (V) \\
200 & 15 & 10 & $\mathrm{~A}$ & Discharge Current (A) \\
200 & 100 & 25 & $\mu \mathrm{s}$ & Pulse on time (Ton) \\
\hline
\end{tabular}

After determining the parameters and the level of each parameter, the procedure of doing the experiments should be determined. 54 experiments $\left(3^{3} \times 2^{2}\right)$ are needed to be carried out with these levels. However, for decreasing of the cost and time-consuming, two kinds of DOE method (Taguchi and optimal determinant method) are selected. In order to design the matrix of Taguchi experiments, MINITAB statistical software was used. Table 3 shows the measured outputs in L18 Taguchi design. In this table, each row represents an experiment. For example, in the first experiment all input parameters should be set in their first level. The measured outputs (MRR and surface roughness) have been inserted in the last two columns. Table 4 shows the matrix of experiments based on the optimal determinant method which is obtained using the Design Expert software. In this design, only one arrangement is suggested by the statistical software.

Table 3: Taguchi Design of Experiments and output parameters

\begin{tabular}{|c|c|c|c|c|c|c|}
\hline \multicolumn{2}{|c|}{ output parameters } & \multicolumn{4}{|c|}{ input parameters } & \multirow[b]{2}{*}{$\begin{array}{l}\text { experiment } \\
\text { number }\end{array}$} \\
\hline $\begin{array}{c}\mathrm{SR} \\
\left(\mathrm{R}_{\mathrm{a}}\right) \\
(\mu \mathrm{m}) \\
\end{array}$ & $\begin{array}{c}\text { MRR } \\
\left(\mathrm{cm}^{3} / \mathrm{min}\right)\end{array}$ & $\begin{array}{l}\mathrm{T}_{\text {Off }} \\
(\mu \mathrm{s})\end{array}$ & $\begin{array}{l}\mathrm{T}_{\text {On }} \\
(\mu \mathrm{s})\end{array}$ & $\begin{array}{c}\mathrm{I} \\
\text { (A) }\end{array}$ & $\begin{array}{l}\mathrm{V} \\
(\mathrm{V})\end{array}$ & \\
\hline 2.830 & 0.00739 & 25 & 25 & 10 & 100 & 1 \\
\hline 3.910 & 0.01217 & 100 & 100 & 10 & 100 & 2 \\
\hline 3.144 & 0.00869 & 200 & 200 & 10 & 100 & 3 \\
\hline 2.864 & 0.02521 & 25 & 25 & 15 & 100 & 4 \\
\hline 4.034 & 0.03737 & 100 & 100 & 15 & 100 & 5 \\
\hline 6.215 & 0.02825 & 200 & 200 & 15 & 100 & 6 \\
\hline 3.867 & 0.02043 & 100 & 25 & 20 & 100 & 7 \\
\hline 6.221 & 0.02781 & 200 & 100 & 20 & 100 & 8 \\
\hline 6.075 & 0.05085 & 25 & 200 & 20 & 100 & 9 \\
\hline 3.438 & 0.00391 & 200 & 25 & 10 & 220 & 10 \\
\hline 3.155 & 0.01347 & 25 & 100 & 10 & 220 & 11 \\
\hline 3.764 & 0.01173 & 100 & 200 & 10 & 220 & 12 \\
\hline 3.220 & 0.02216 & 100 & 25 & 15 & 220 & 13 \\
\hline 4.585 & 0.02173 & 200 & 100 & 15 & 220 & 14 \\
\hline 4.308 & 0.04042 & 25 & 200 & 15 & 220 & 15 \\
\hline 4.683 & 0.01217 & 200 & 25 & 20 & 220 & 16 \\
\hline 3.762 & 0.05519 & 25 & 100 & 20 & 220 & 17 \\
\hline 6.463 & 0.04302 & 100 & 200 & 20 & 220 & 18 \\
\hline
\end{tabular}

\section{Results and Discussion}

\subsection{Analysis based on the data of Taguchi design}

Taguchi experimental design has been proposed basically for signal-to-noise analysis. This method is a powerful tool in statistical analysis of the experimental data. In each experiment, we must always seek the highest $\mathrm{S} / \mathrm{N}$ ratio in the results according to Taguchi (2005). The high amount of $\mathrm{S} / \mathrm{N}$ indicates that the effect of controllable parameters is more than the effect of uncontrollable ones. The design of manufacturing process with the highest ratio always leads to an optimal quality with the least variance. In Taguchi method, after determining the input and output parameters and their values, the data and observations are converted to a number ( $\mathrm{S} / \mathrm{N}$ ratio) in two steps. In the first step, mean square deviation (MS) is calculated which is a statistical quantity and shows the deviation from the characteristic value. According to the problem conditions, this function has different states/modes according to Taguchi (2005). Two states used in this research are as follows:

The effect of electrical discharge machining parameters on alloy DIN 1.2080 using the Taguchi method . . . 
A. The smaller number is better: in the measurement of the surface roughness, the smaller the number, the better is the situation. Thus, to calculate the loss function, formula (1) is used that presented in Minitab Software Web (2015):

$$
\mathrm{S} / \mathrm{N}=-10 \times \log \left(\sum_{\mathrm{i}=1}^{\mathrm{n}}\left(1 / \mathrm{Y}_{\mathrm{i}}^{2}\right) / \mathrm{n}\right)
$$

B. The bigger number is better: in the measurement of the material removal rate, the larger number is better. Thus, Thus, to calculate the loss function, formula (2) is used that presented in Minitab Software Web (2015):

$$
\mathrm{S} / \mathrm{N}=-10 \times \log \left(\sum_{\mathrm{i}=1}^{\mathrm{n}}\left(\mathrm{Y}_{\mathrm{i}}^{2}\right) / \mathrm{n}\right)
$$

Table 5 shows $\mathrm{S} / \mathrm{N}$ ratios for all output parameters of machining:

Table 5: $\mathrm{S} / \mathrm{N}$ ratios for output parameters

\begin{tabular}{ccccc}
\hline & & \multicolumn{2}{c}{ output parameters } & \\
\cline { 3 - 4 } S/N for SR & S/N for MRR & SR & \multirow{2}{*}{ MRR } & experiment number \\
\hline-9.0357 & -42.6271 & 2.830 & 0.00739 & 1 \\
-11.8435 & -38.2942 & 3.910 & 0.01217 & 2 \\
-9.9497 & -41.2196 & 3.144 & 0.00869 & 3 \\
-9.1395 & -31.9685 & 2.864 & 0.02521 & 4 \\
-12.1147 & -28.5495 & 4.034 & 0.03737 & 5 \\
-15.8688 & -30.9796 & 6.215 & 0.02825 & 6 \\
-11.7475 & -33.7946 & 3.867 & 0.02043 & 7 \\
-15.8772 & -31.1160 & 6.221 & 0.02781 & 8 \\
-15.6709 & -25.8742 & 6.075 & 0.05085 & 9 \\
-10.7261 & -48.1565 & 3.438 & 0.00391 & 10 \\
-9.9800 & -37.4126 & 3.155 & 0.01347 & 11 \\
-11.5130 & -38.6140 & 3.764 & 0.01173 & 12 \\
-10.1571 & -33.0886 & 3.220 & 0.02216 & 13 \\
-13.2268 & -33.2588 & 4.585 & 0.02173 & 14 \\
-12.6855 & -27.8681 & 4.308 & 0.04042 & 15 \\
-13.4105 & -38.2942 & 4.683 & 0.01217 & 16 \\
-11.5084 & -25.1628 & 3.762 & 0.05519 & 17 \\
-16.2087 & -27.3266 & 6.463 & 0.04302 & 18 \\
\hline
\end{tabular}

\subsubsection{Determining the optimal levels of parameters for material removal rate}

One of the advantages of $\mathrm{S} / \mathrm{N}$ method is the possibility to determine the level of each parameter for the optimization of the intended output. According to Figure 3, the level with the highest mean of S/N ratio is the optimal level to maximize material removal rate.

Therefore, to achieve maximum material removal rate, voltage and pulse off time must be in their first level, while the other two parameters should be set on their high levels. Hence, the optimal levels for the maximization of material removal rate in the EDM of DIN 1.2080 alloy include: $V_{1} I_{3} T_{o n 3} T_{\text {off }}$. Selecting high levels of current intensity maximizes the discharged energy rate on the surface of the workpiece and, through melting and evaporating larger quantities of the workpiece, increases MRR. Regarding pulse on time, it can be said that this parameter determines the time of the creation and presence of the spark between the electrode and the workpiece; by increasing this parameter, more amount is removed from the work surface in each cycle and, hence, material removal rate will be increased. In the pulse off time, the current is cut off and the particles exfoliated from the metal surface are removed from the place by dielectric fluid. The less is this parameter, the more will be the average number of sparks per unit of time and, hence, material removal rate is increased. Voltage plays no key role in material removal rate and its only function is to cause the ionization process be performed at the desired speed. This facilitates the control of servo motor. 


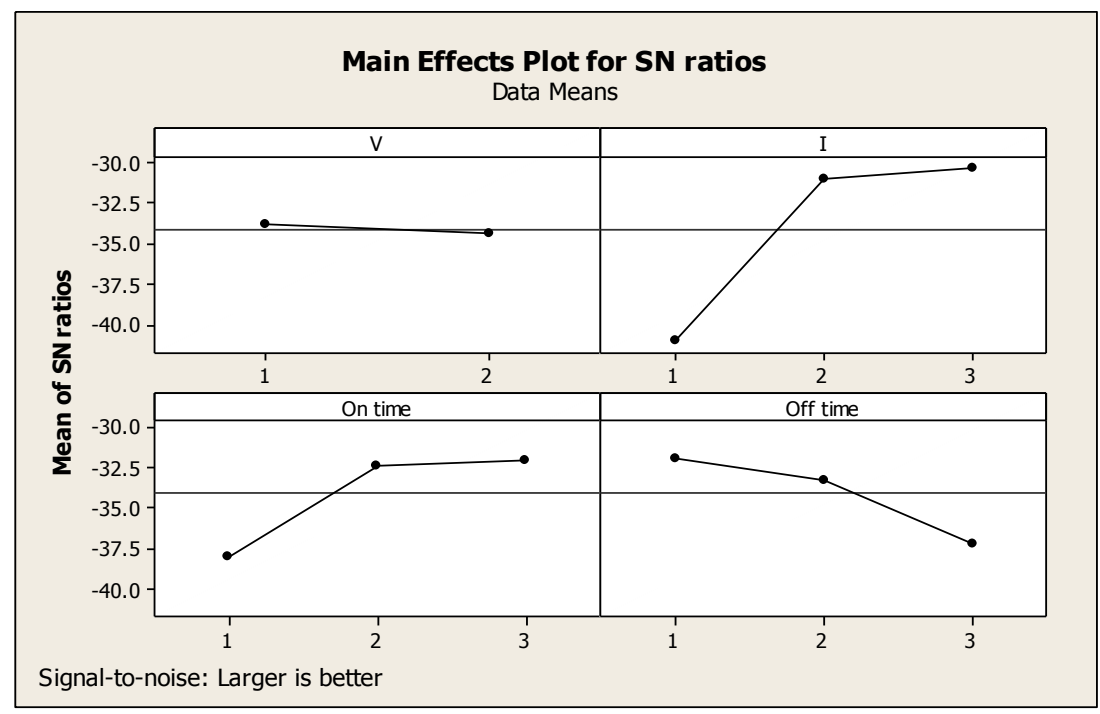

Figure 3: Main Effects Plot for Means - Material Removal Rate

Finally, through verification test, the accuracy of prediction of S/N method was measured (See Table 7). As can be seen the prediction error is about $6 \%$. This error is due to the effect of environmental factors and other uncontrollable parameters on the machining process. Because of the uncertainties involved in electrical discharge machining and its industrial nature, this amount of prediction error is acceptable.

Table 7: Calculation error of Taguchi analysis and experimental result (MRR)

\begin{tabular}{lccc}
\hline Optimal levels & $\mathrm{S} / \mathrm{N}$ ratio of experimental result & Prediction Analysis of Taguchi & error \% \\
\hline $\mathrm{V}_{1} \mathrm{I}_{3} \mathrm{~T}_{\text {on3 }} \mathrm{T}_{\text {off1 }}$ & 0.0503 & 0.04807 & 5.7832 \\
\hline
\end{tabular}

Another advantage of the S/N method is that it determines the influence of each parameter in the desired output. To this end, analysis of variance for the data related to material removal rate can be used (See Table 8). In this table, the degree of freedom is defined for each individual input parameter separately which is equal to the number of its levels minus one.

Table 8: Analysis of Variance for Material Removal Rate

\begin{tabular}{cccccc}
\hline Source & DF & Adj SS & Adj MS & F & P \\
\hline V & 1 & 1.258 & 1.258 & 1.71 & 0.220 \\
I & 2 & 438.009 & 219.004 & 219.46 & 0.000 \\
On time & 2 & 137.128 & 68.564 & 93.44 & 0.000 \\
Off time & 2 & 91.852 & 45.926 & 62.59 & 0.000 \\
Residual Error & 10 & 7.338 & 0.734 & $\ldots$. & $\ldots$. \\
Total & 17 & $\ldots$. & $\ldots$. & $\ldots$. & $\ldots$. \\
\hline
\end{tabular}

- P-value: the probability of P-value is one of the methods to assess the suitability of the model. An easy way to control each parameter is to compare the P-value in the last column of all analysis of variance tables with the risk of error $(\alpha)$. If $\mathrm{P}$-value $<\alpha$, the assumption of the effectiveness of the parameter is confirmed, and if $\mathrm{P}$-value $>\alpha$, this assumption is rejected. Given the fact that the risk of error is considered $5 \%$ in this research, P-value confirms the effectiveness of all parameters except voltage.

- F-value: this value should be compared with its critical value $\left(\mathrm{F}_{\mathrm{a}, \mathrm{k}, \mathrm{n}-\mathrm{k}-1}\right)$. To verify the effectiveness of each parameter, the following proportional relationship should be established: $\mathrm{F}_{0}>\mathrm{F}_{\mathrm{a}, \mathrm{k}, \mathrm{n}-\mathrm{k}-\mathrm{l}}$. In calculating the critical value, $\mathrm{k}$ is the degree of freedom of the related parameter and $\mathrm{n}$ is the number of experiments (here 18). On the other hand, larger values of this statistic suggest more effectiveness of it. Critical F-value of the statistic tables is equal to 4.94 for the voltage parameter $\left(\mathrm{F}_{0.05,1,16}\right)$ and equal to 3.86 for the other three parameters $\left(\mathrm{F}_{0.05,2,15}\right)$. Hence, this value also shows the ineffectiveness of the voltage parameter. Finally, 
the comparison plots of the experimental results and the predicted results of Taguchi analysis have been provided for the output of material removal rate (See Figure 4):
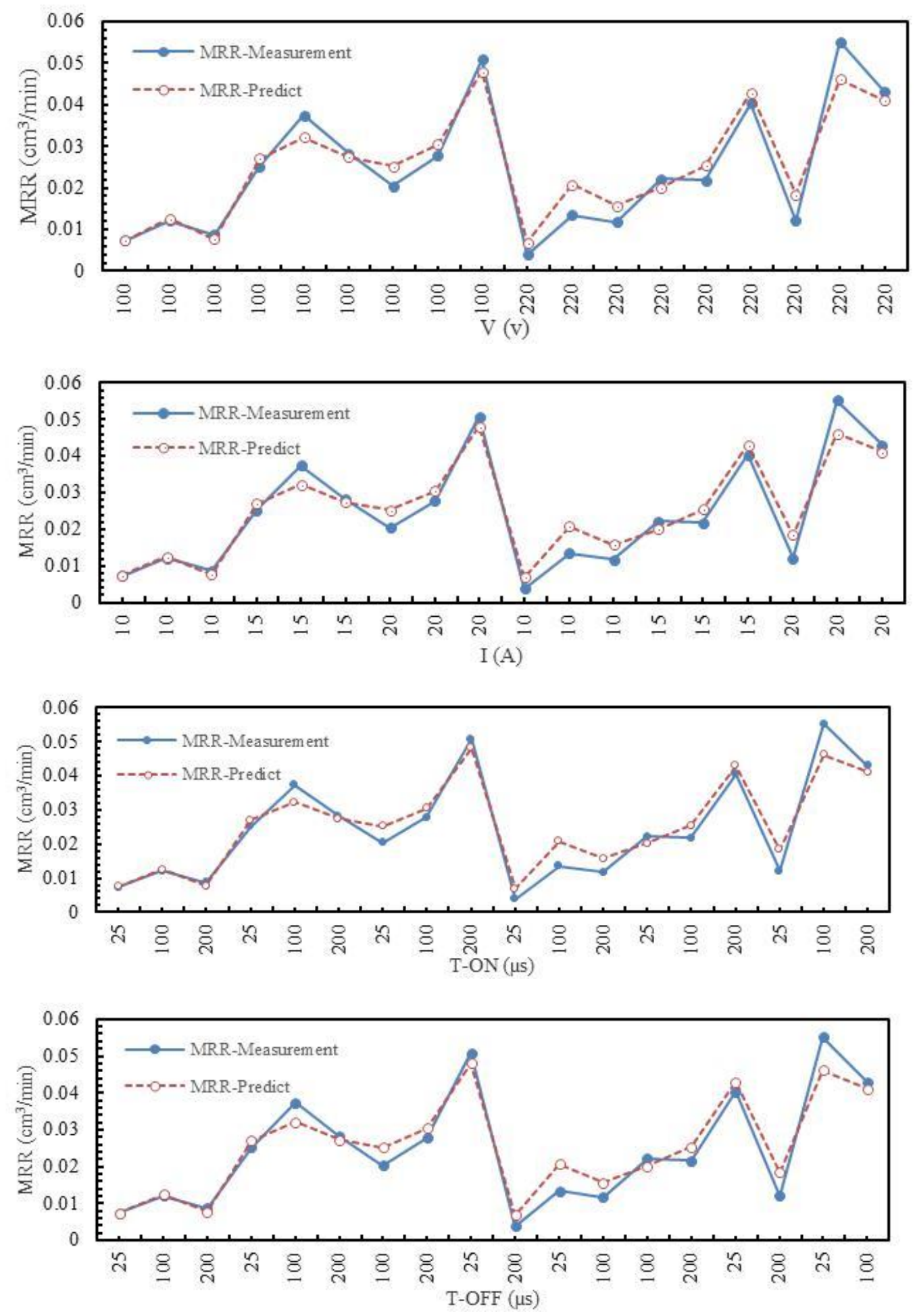

Figure 4: Comparison plots of the experimental results and the predicted results of Taguchi analysis for the output of material removal rate

\subsubsection{Determination of the optimal levels of the parameters for surface roughness}

According to the Figure 5, the level with the highest average value of $\mathrm{S} / \mathrm{N}$ is the best level for the related parameter in the optimization of surface quality. 


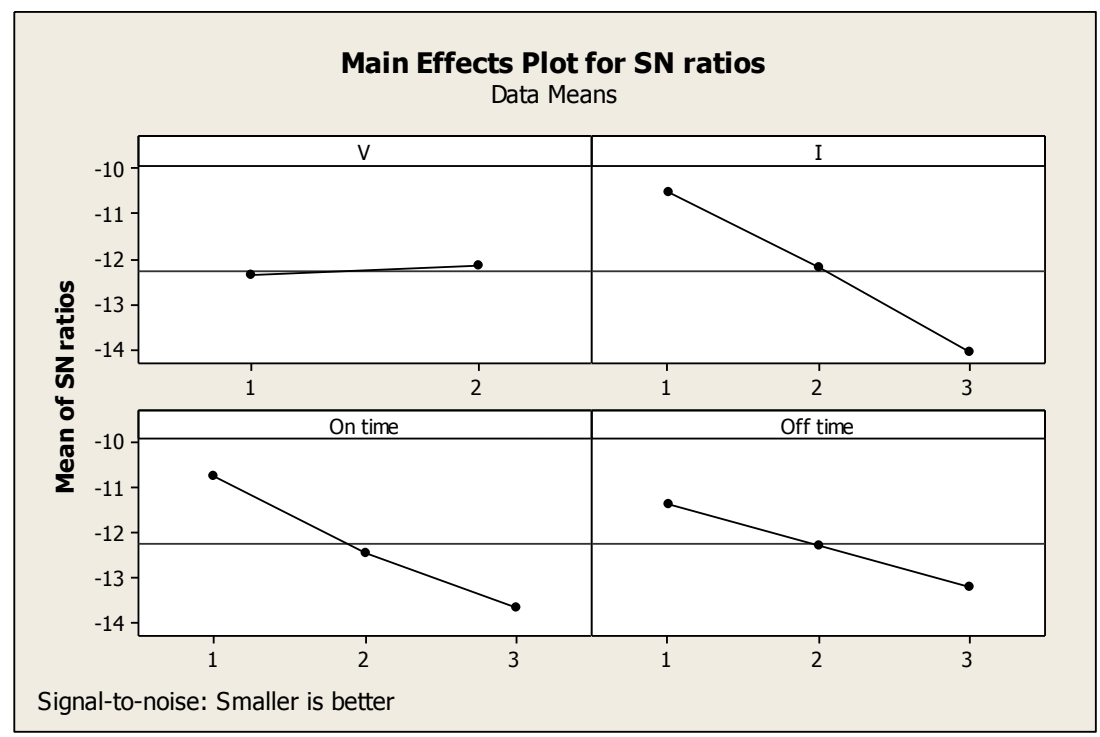

Figure 5: Main effects plot for surface roughness

Therefore, the optimal levels for the reduction of surface roughness in EDM of DIN 1.2080 alloys include $V_{2} I_{1}$ $\mathrm{T}_{\text {on1 }} \mathrm{T}_{\text {off1 } 1}$. In order to assess the accuracy of prediction in this output, verification experiment was performed according to the optimal levels. As is shown in Table 9, the error of prediction is less than $6 \%$.

Table 9: Calculation error of Taguchi analysis and experimental result (SR)

\begin{tabular}{cccc}
\hline Optimal levels & $\mathrm{S} / \mathrm{N}$ ratio of experimental result & Prediction Analysis of Taguchi & error \% \\
\hline $\mathrm{V}_{2} \mathrm{I}_{1} \mathrm{~T}_{\text {on } 1} \mathrm{~T}_{\text {off } 1}$ & 2.214 & 2.086 & 5.136 \\
\hline
\end{tabular}

According to the above plot and the results of the analysis of variance (See Table 10), it can be said that voltage has a low effect on surface roughness, and the increase of pulse current leads to the increase of spark energy that in turn increases the surface roughness. For voltage, the $\mathrm{S} / \mathrm{N}$ ratio is not so much different in two levels; however, its second level is considered as the optimal level. Moreover, the first level in the parameters of current intensity, pulse on time, and pulse off time is determined as the optimal level. It is due to the reduction of spark energy, separation of smaller particles from the workpiece, and, finally, the reduction of surface roughness.

Table 10: Analysis of Variance for Surface Roughness

\begin{tabular}{cccccc}
\hline Source & DF & Adj SS & Adj MS & F & P \\
\hline V & 1 & 0.186 & 1.186 & 0.09 & 0.767 \\
I & 2 & 38.107 & 19.054 & 9.50 & 0.000 \\
On time & 2 & 26.297 & 13.149 & 6.56 & 0.000 \\
Off time & 2 & 10.155 & 5.078 & 2.53 & 0.129 \\
Residual Error & 10 & 20.52 & 2.005 & $\ldots$. & $\ldots$. \\
Total & 17 & $\ldots$. & $\ldots$. & $\ldots$. & $\ldots$. \\
\hline
\end{tabular}

Based on what was mentioned in the analysis of material removal rate, P-value confirms the effectiveness of the parameters of current intensity and pulse on time; but, voltage and pulse off time have no effect on the quality of the workpiece surface. Critical F-value of the statistic tables is equal to 4.49 for the voltage parameter $\left(\mathrm{F}_{0.05,1,16}\right)$ and equal to 3.68 for the other three parameters $\left(\mathrm{F}_{0.05,2,15}\right)$. Thus, this value also shows the ineffectiveness of the voltage and pulse off time parameters. Current intensity and voltage, respectively, have the highest and lowest impact on surface roughness. The high impact of the current intensity on surface quality is due to the fact that reduced current intensity greatly reduces the amount of spark energy and, thus, a lower amount of workpiece surface is melted and vaporized in each pulse. Therefore, the depth of surface cavities is reduced, which means reduced surface roughness. In addition to the reasons mentioned previously, another reason that voltage change may not have a significant effect on machining characteristics is that the voltage 
which is set on the machine is the power supply voltage (open-circuit voltage) and machining crater voltage, where the spark occurs, is usually $20-25 \%$ of this voltage. With a good accuracy, Taguchi analysis can determine the optimal levels of setting parameters for each intended output. Moreover, the effect of input parameters on the quality characteristics of the process can be calculated in this way. However, Taguchi analysis is only able to select the best levels among those given in the experiments. This is while, if the variables are contiguous or have multiple levels, Taguchi analysis cannot be used to determine the exact levels of the parameters. Among the limitations of this method mention may be made of the difficulty of multiobjective optimization. Finally, the comparison plots of the experimental results and the predicted results of Taguchi analysis have been provided for the output of surface roughness (See Figure 6):
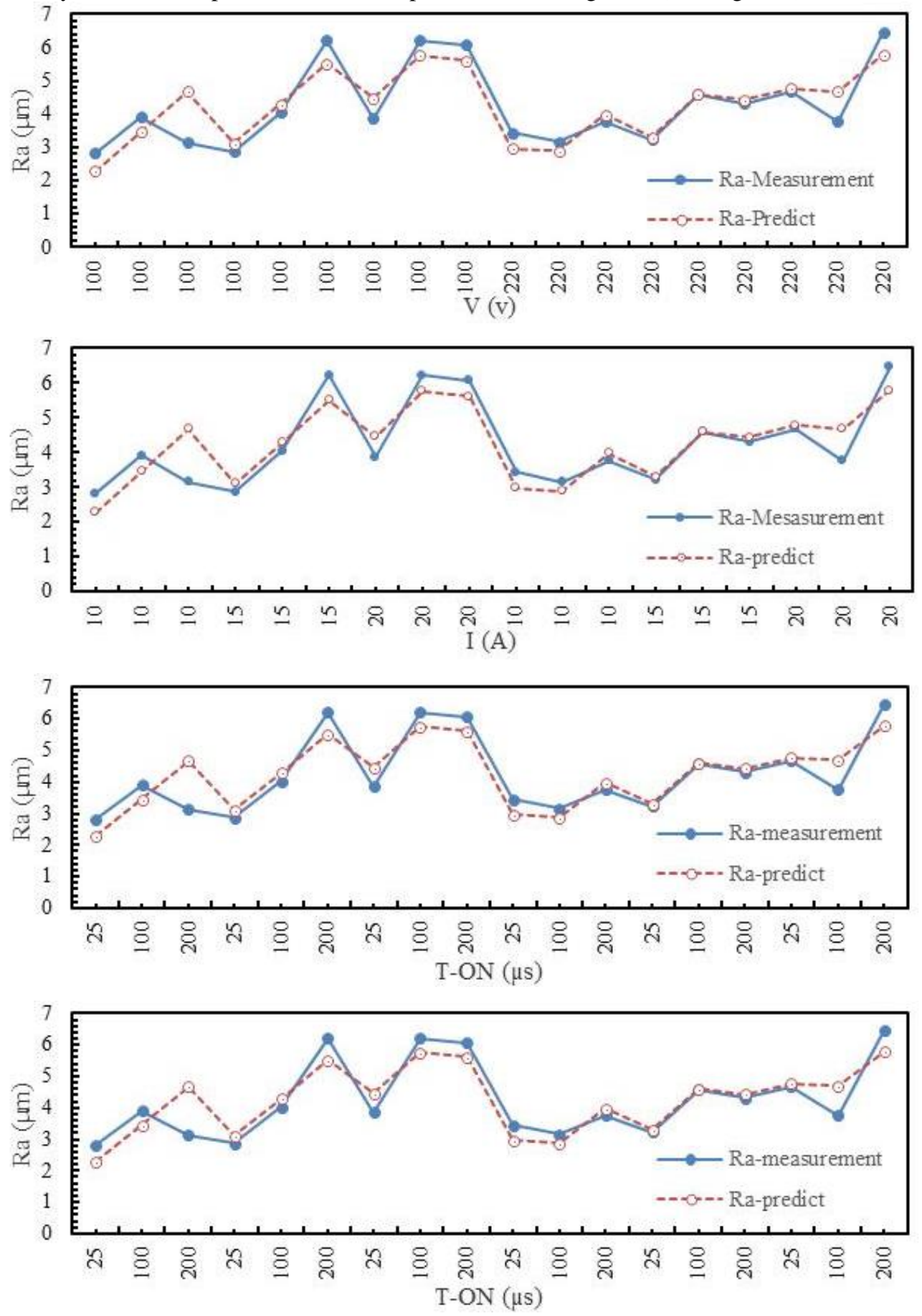

Figure 6: Comparison plots of the experimental results and the predicted results of Taguchi analysis for the output of surface roughness 
In the next step, using the data of optimal matrix, the modeling and optimization of the process was done to compare the results of these two methods together.

\subsection{Analysis of the results based on the data of optimal determinant}

For the regression modeling it had better not use the Taguchi design matrix, because Taguchi experimental design is naturally used for analysis with the help of other statistical methods such as $\mathrm{S} / \mathrm{N}$ analysis. Hence, in this section, using the data of optimal determinant matrix, regression modeling of the process is performed. A regression model is an equation which compares the changes in the dependent variable (response variable) with those in the independent variable based on a polynomial mathematical equation. A regression model which is composed of more than one variable is called multivariate regression model. According to the research conducted on modeling of manufacturing processes, different types of regression models including first-order (linear), Quadratic (second-order), Curvilinear (modified second-order), and exponential model were used in this research. The general form of linear regression model, which is one of the most common multivariate regression models, is shown through the formula (3):

$$
Y=b_{0}+\sum_{i=1}^{n} b_{i} X_{i}
$$

In the above equation, $\mathrm{X} 1, \mathrm{X} 2, \ldots \ldots, \mathrm{Xn}$ are the input variables and $b i$ refers to the regression coefficients which should be determined according to the data. $\mathrm{Y}$ is the response variable (output). In some multivariate regression models, interaction and higher levels of input variables are considered too. These regression models are referred to as linear second-order (or higher) polynomial regression. The general form of second-order polynomial model is offered as follows:

$$
Y=b_{0}+\sum_{i=1}^{n} b_{i} X_{i}+\sum_{i=n}^{2 n} b_{i} X_{i}^{2}+\sum_{i=1}^{n} \sum_{j=1}^{n} b_{i, j} X_{i} X_{j}
$$

Similarly, equation (5) represents the general form of the exponential regression equation with two input and one output variables.

$$
Y=a \cdot X_{1}^{b} \cdot X_{2}^{g}
$$

For the above equation, if logarithm is taken from both sides, the given model will be linear.

$$
\log (Y)=\log (a)+b \log \left(X_{1}\right)+g \log \left(X_{2}\right)
$$

Sometimes, through deleting the parameters which have little effect in the model, it is possible to achieve higher correlation coefficients. The resulting model is known as the modified model. For a particular system, so much regression models can be achieved. The best model should be selected from among them through appropriate criteria. Research on the model validation is an important part of regression modeling process. To determine the accuracy and appropriateness of a regression model, different techniques are used some of the most important of which are mentioned below that presented by Minitab Company (2015):

A. Randomness and normal distribution of residuals (using histogram of residuals and normal probability plot of the residuals)

B. The independence of residuals based on the implementation order (using analysis of plots)

C. The independence of residuals in the factor levels (is obtained using plot analysis)

D. The correlation coefficient of R-sq R-adj R-pred (indicates the intensity of correlation between input and output variables).

\subsubsection{Regression modeling of material removal rate}

At this point, the effect of linear, Quadratic, Curvilinear, and the Logarithmic regression models on the data obtained from the experiment of design were separately introduced for the output variable of material removal rate. To validate and ensure the accuracy of the created models, apart from the designed experiments, some other experiments were carried out and the obtained results were compared with the output values of the models (See Table 11). Finally, with regard to the methods described for the detection of the accuracy and appropriateness of the regression model as well as by examining the average error for each model, the best models were selected for the investigation of material removal rate and surface roughness. 
Table 11: validation of removal rate models

\begin{tabular}{|c|c|c|c|c|c|c|c|c|c|c|c|}
\hline \multirow{2}{*}{ model } & \multirow{2}{*}{$\begin{array}{l}\% \mathrm{R}- \\
\text { pred }\end{array}$} & \multirow{2}{*}{$\begin{array}{l}\% R- \\
\text { adj }\end{array}$} & \multirow{2}{*}{$\begin{array}{c}\% \mathrm{R}- \\
\mathrm{sq}\end{array}$} & \multicolumn{4}{|c|}{ input parameters } & \multirow{2}{*}{$\begin{array}{l}\text { Predicted } \\
\text { value }\end{array}$} & \multirow{2}{*}{$\begin{array}{l}\text { Experimental } \\
\text { value }\end{array}$} & \multirow{2}{*}{ error } & \multirow{2}{*}{$\begin{array}{l}\text { Mean } \\
\text { error }\end{array}$} \\
\hline & & & & $\mathrm{T}_{\text {off }}$ & $\mathrm{T}_{\text {on }}$ & $\mathrm{I}$ & $\mathrm{V}$ & & & & \\
\hline \multirow{3}{*}{$\begin{array}{l}\text { model } \\
\text { Linear }\end{array}$} & \multirow{3}{*}{63.61} & \multirow{3}{*}{71.26} & \multirow{3}{*}{75.80} & 25 & 25 & 10 & 100 & 0.00869 & 0.00739 & 17.592 & \multirow{3}{*}{7.156} \\
\hline & & & & 200 & 100 & 20 & 100 & 0.02737 & 0.02781 & 1.588 & \\
\hline & & & & 100 & 200 & 20 & 220 & 0.04400 & 0.04302 & 2.288 & \\
\hline \multirow{3}{*}{ Quadratic } & \multirow{3}{*}{85.23} & \multirow{3}{*}{92.81} & \multirow{3}{*}{96.55} & 25 & 25 & 10 & 100 & 0.00616 & 0.00739 & 16.590 & \multirow{3}{*}{9.273} \\
\hline & & & & 200 & 100 & 20 & 100 & 0.02675 & 0.02781 & 3.802 & \\
\hline & & & & 100 & 200 & 20 & 220 & 0.03982 & 0.04302 & 7.427 & \\
\hline \multirow{3}{*}{ Curvilinear } & \multirow{3}{*}{92.30} & \multirow{3}{*}{94.16} & \multirow{3}{*}{95.79} & 25 & 25 & 10 & 100 & 0.00675 & 0.00739 & 8.671 & \multirow{3}{*}{6.042} \\
\hline & & & & 200 & 100 & 20 & 100 & 0.02647 & 0.02781 & 4.825 & \\
\hline & & & & 100 & 200 & 20 & 220 & 0.03982 & 0.04302 & 4.631 & \\
\hline \multirow{3}{*}{ Logarithmic } & \multirow{3}{*}{72.29} & \multirow{3}{*}{78.66} & \multirow{3}{*}{82.07} & 100 & 100 & 10 & 100 & 0.00856 & 0.00739 & 15.796 & \multirow{3}{*}{8.306} \\
\hline & & & & 200 & 100 & 20 & 100 & 0.02810 & 0.02781 & 1.001 & \\
\hline & & & & 100 & 200 & 20 & 220 & 0.04682 & 0.04302 & 8.12 & \\
\hline
\end{tabular}

Because of lower absolute average error in the curvilinear model, this model is selected as material removal rate evaluation model in EDM of DIN 1.2080 alloy. Although R-sqr in this model is lower than the Quadratic model, it has much better prediction accuracy. This is due to the high R-sq (pred) and R-Sq (Adj) in this model. Thus, it can be concluded that the model is suitable for prediction which has a greater R-sq (pred) and R-Sq (Adj) respectively. As previously mentioned, in this section, other statistical analysis will be examined for the selected model. To this end, the selected model's full table of analysis of variance (See Table 12) and residual plots (See Figure 5) were used.

Table 12: Analysis of variance of the Curvilinear model for material removal rate

\begin{tabular}{|c|c|c|c|c|c|}
\hline \multicolumn{4}{|c|}{$\begin{aligned} \text { MRR }= & -0.0871864+0.000221514 \text { on }+0.0119795 \mathrm{i}-1.09938 \mathrm{e}-006 \text { on } \times \text { on }+3.08253 \mathrm{e}- \\
& 007 \text { on } \times \text { off }+4.60924 \mathrm{e}-006 \mathrm{i} \times \text { on }-0.000300337 \mathrm{i} \times \mathrm{i}-8.08543 \mathrm{e}-006 \mathrm{i} \times \text { off }\end{aligned}$} & \multicolumn{2}{|c|}{ model } \\
\hline Source & DF & Seq SS & MS & $\mathrm{F}$ & $\mathrm{p}$ \\
\hline regression & 7 & 0.00493 & 0.00070 & 58.5654 & 0.0000 \\
\hline $\mathrm{T}_{\text {on }}$ & 1 & 0.00042 & 0.00016 & 13.2591 & 0.0019 \\
\hline $\mathrm{I}$ & 1 & 0.00255 & 0.00054 & 45.2024 & 0.0000 \\
\hline $\mathrm{T}_{\mathrm{on}} \times \mathrm{T}_{\mathrm{on}}$ & 1 & 0.0034 & 0.00039 & 32.5334 & 0.0000 \\
\hline $\mathrm{T}_{\mathrm{on}} \times \mathrm{T}_{\mathrm{off}}$ & 1 & 0.00050 & 0.00008 & 6.3488 & 0.0214 \\
\hline $\mathrm{I} \times \mathrm{I}$ & 1 & 0.00031 & 0.00033 & 27.3706 & 0.0001 \\
\hline $\mathrm{I} \times \mathrm{T}_{\text {off }}$ & 1 & 0.00076 & 0.00073 & 60.6185 & 0.0000 \\
\hline $\mathrm{I} \times \mathrm{T}_{\text {on }}$ & 1 & 0.00004 & 0.00004 & 4.6840 & 0.0409 \\
\hline Error & 18 & 0.00022 & 0.00001 & & \\
\hline total & 25 & 0.00515 & & & \\
\hline $\mathrm{R}-\mathrm{sq}=95.79 \%$ & & $R-s q(\operatorname{adj})=94.16 \%$ & $\mathrm{R}-\mathrm{sq}(\mathrm{p}$ & $d)=92.30$ & \\
\hline
\end{tabular}

- P-value: confirms the suitability of this model and its parameters.

- F-value: should be compared with its critical value $\left(\mathrm{F}_{\alpha, \mathrm{k}, \mathrm{n}-\mathrm{k}-1}\right)$. To confirm the suitability of the intended model, $\mathrm{F}_{0}>\mathrm{F}_{\alpha, \mathrm{k}, \mathrm{n}-\mathrm{k}-1}$ should be established. In the calculation of critical value, $\mathrm{k}$ is the degree of freedom of regression sum of squares (here 7 ) and $\mathrm{n}$ is the number of experiments. Using statistical tables, $\mathrm{F}_{0.05,7,18}$ is equal to 2.58 and $\mathrm{F}_{0.05,1,24}$ is equal to 4.26 . Given that $\mathrm{F}_{0}$ is equal to 58.5654 for the Curvilinear model and is higher than its critical level in input parameters, it also confirms the suitability of the model and its coefficients. In the full tables obtained from the linear, Quadratic, and Logarithmic models, P and F values show the ineffectiveness of the voltage on material removal rate.

Residual plots: Figure 7 shows the residual plots for the Curvilinear model of material removal rate. Figure (A) shows the normal probability plot of residuals. This plot has an ideal state since it is as a 
straight line with constant slope. In Figure (B), the plot should be symmetrical to the zero point and the points around this point should be scattered steadily; hence, the residual normal plot indicates that the residual distribution has been incidental and does not follow any particular trend. Figure (C) shows the residual histogram that based on its height (width) and ideal bell-shape form, the area of frequency/distribution can be judged. In the following plot it can be seen that the frequency/distribution is relatively desirable and normal distribution is acceptable. In Figure (D), the residual plots should randomly fluctuate around the center line; therefore, it can be observed that all the standardized residuals are in an appropriate range/interval.

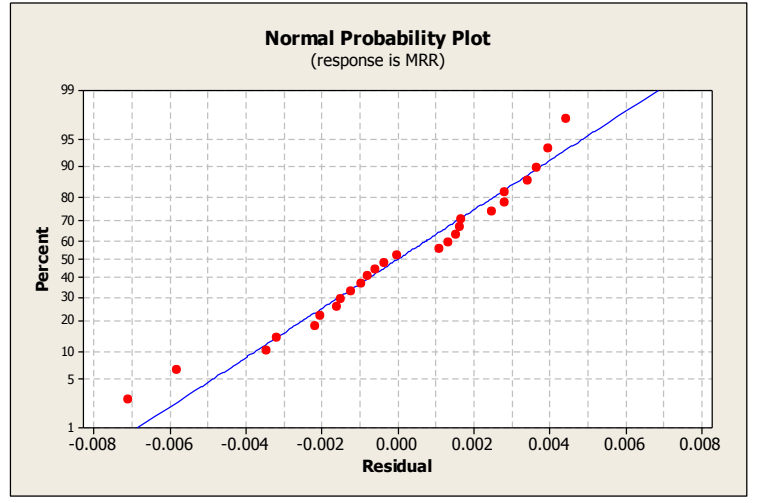

(A)

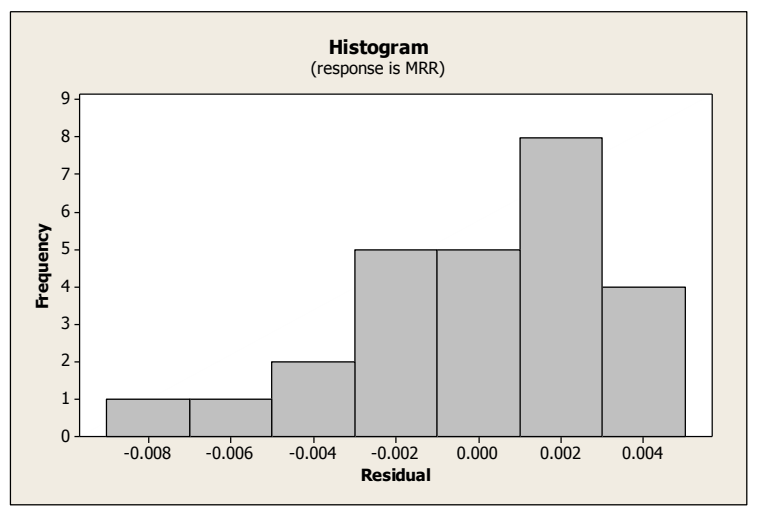

(C)

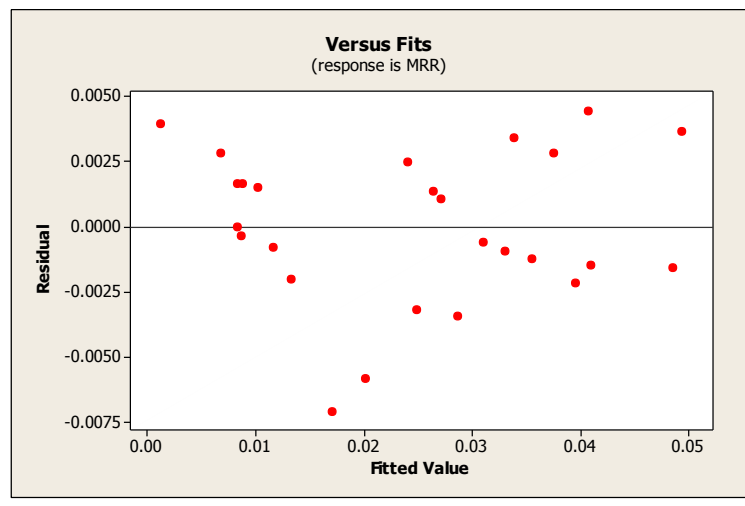

(B)

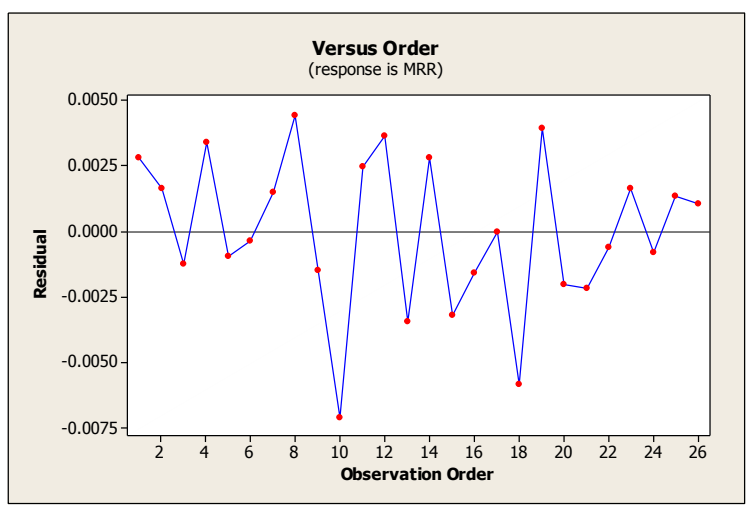

(D)

Figure 7: Residual plots for the curvilinear model of material removal rate

- The optimization of material removal rate: According to the levels of input parameters used in this experiment and using the obtained regression model, the model output has been calculated for all possible states (a combination of 54 setting variables $\left(2^{1} \times 3^{3}\right)$ ). Since the aim is to maximize material removal rate, the maximum output will be related to $\mathrm{V}_{1} \mathrm{I}_{3} \mathrm{~T}_{\text {on2 }} \mathrm{T}_{\text {off } 1}$ levels. In order to validate the optimization results, at the end, the predicted optimal levels were set up on the machine and re-experimented (See Table 13).

Table 13: the optimization of material removal rate

\begin{tabular}{lccc}
\hline Optimal levels & Experimental value & Predicted value & error \% \\
\hline $\mathrm{V}_{1} \mathrm{I}_{3} \mathrm{~T}_{\text {on2 }} \mathrm{T}_{\text {off } 1}$ & 0.05217 & 0.04939 & 5.328 \\
\hline
\end{tabular}

As can be seen, model prediction with actual value has less than $6 \%$ error, indicating the high precision of the model in predicting material removal rate in EDM of DIN 1.2080 alloy. Finally, the comparison plots of the experimental results and the prediction results of the regression model have been provided for the output of material removal rate (See Figure 8): 

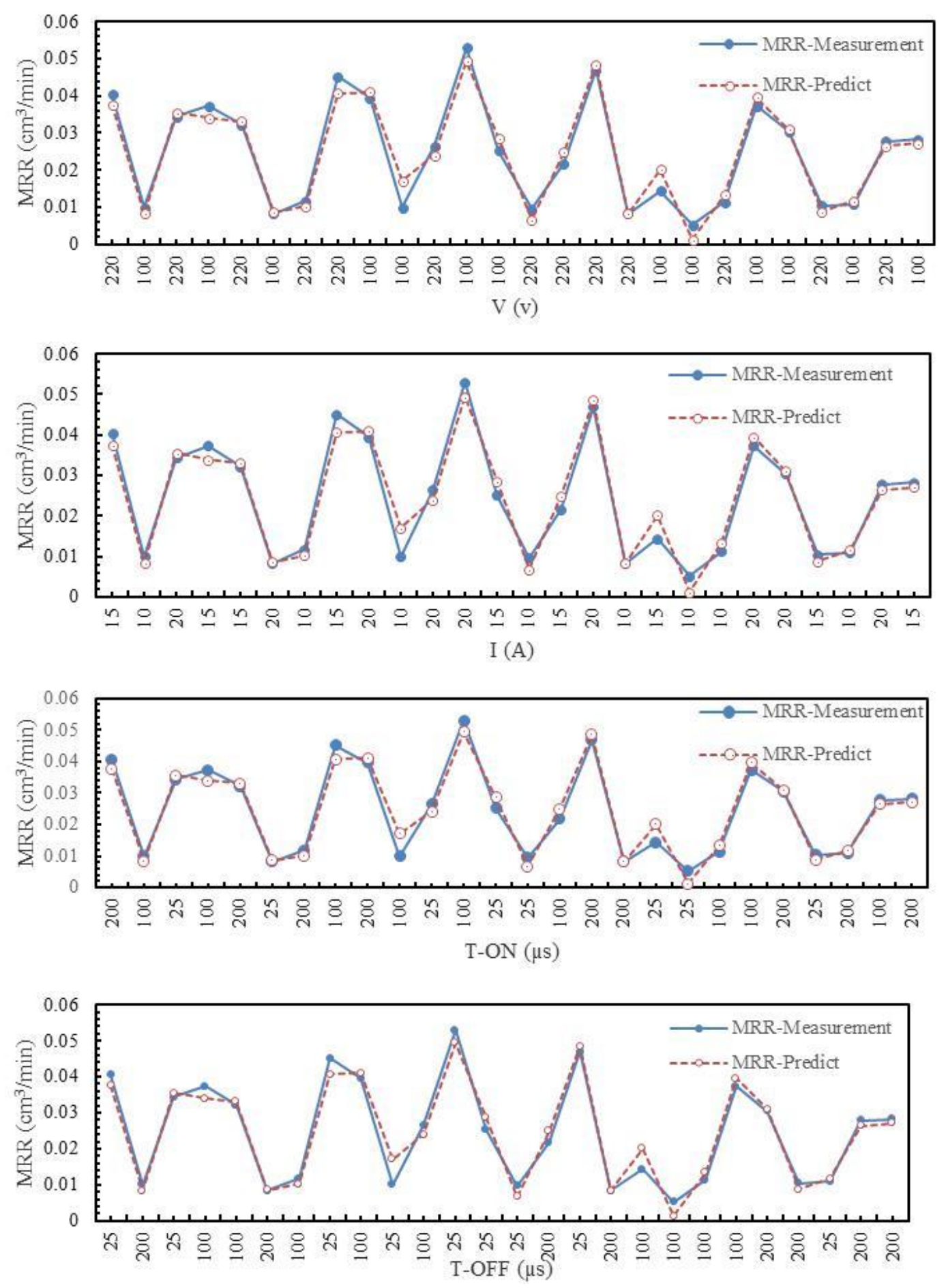

Figure 8: The comparison plots of the experimental results and the prediction results of the regression model for the output of material removal rate

\subsubsection{Statistical modeling of surface roughness}

At this point, the effect of linear, Quadratic, Curvilinear, and the Logarithmic regression models on the data obtained from the experiment of design were separately introduced for the output variable of material removal rate. Then, as previous stage, through doing some experiments, apart from the designed ones, each model was validated (See Table 14). 
Table 14: Validation of surface roughness regression models

\begin{tabular}{|c|c|c|c|c|c|c|c|c|c|c|c|}
\hline \multirow{2}{*}{ model } & \multirow{2}{*}{$\begin{array}{l}\% \mathrm{R}- \\
\text { pred }\end{array}$} & \multirow{2}{*}{$\begin{array}{l}\% \mathrm{R}- \\
\text { adj }\end{array}$} & \multirow{2}{*}{$\begin{array}{c}\% \mathrm{R}- \\
\mathrm{sq}\end{array}$} & \multicolumn{4}{|c|}{ input parameters } & \multirow{2}{*}{$\begin{array}{l}\text { Predicted } \\
\text { value }\end{array}$} & \multirow{2}{*}{$\begin{array}{l}\text { Experimental } \\
\text { value }\end{array}$} & \multirow{2}{*}{ error } & \multirow{2}{*}{$\begin{array}{l}\text { Mean } \\
\text { error }\end{array}$} \\
\hline & & & & Toff & Ton & I & $\mathrm{V}$ & & & & \\
\hline \multirow{3}{*}{ Linear } & \multirow{3}{*}{78.39} & \multirow{3}{*}{83.44} & \multirow{3}{*}{86.09} & 25 & 25 & 10 & 100 & 1.850 & 2.830 & 34.629 & \multirow{3}{*}{17.093} \\
\hline & & & & 25 & 100 & 10 & 220 & 2.681 & 3.155 & 15.024 & \\
\hline & & & & 100 & 200 & 20 & 220 & 6.568 & 6.463 & 1.625 & \\
\hline \multirow{3}{*}{ Quadratic } & \multirow{3}{*}{84.72} & \multirow{3}{*}{92.59} & \multirow{3}{*}{96.45} & 25 & 25 & 10 & 100 & 2.456 & 2.830 & 13.215 & \multirow{3}{*}{5.825} \\
\hline & & & & 25 & 100 & 10 & 220 & 3.222 & 3.155 & 2.124 & \\
\hline & & & & 100 & 200 & 20 & 220 & 6.601 & 6.463 & 2.135 & \\
\hline \multirow{3}{*}{ Curvilinear } & \multirow{3}{*}{95.85} & \multirow{3}{*}{93.90} & \multirow{3}{*}{95.85} & 25 & 25 & 10 & 100 & 2.688 & 2.830 & 5.018 & \multirow{3}{*}{4.282} \\
\hline & & & & 25 & 100 & 10 & 220 & 3.075 & 3.155 & 3.536 & \\
\hline & & & & 100 & 200 & 20 & 220 & 6.805 & 6.463 & 5.292 & \\
\hline \multirow{3}{*}{ Logarithmic } & \multirow{3}{*}{85.44} & \multirow{3}{*}{88.87} & \multirow{3}{*}{90.65} & 25 & 25 & 10 & 100 & 2.084 & 2.830 & 26.360 & \multirow{3}{*}{10.489} \\
\hline & & & & 25 & 100 & 10 & 220 & 3.110 & 3.155 & 1.426 & \\
\hline & & & & 100 & 200 & 20 & 220 & 6.701 & 6.463 & 3.682 & \\
\hline
\end{tabular}

According to the validation results, the curvilinear model was selected as the best model for evaluating the surface roughness. Table 15 shows analysis of variance of the curvilinear regression model for surface roughness.

Table 15: Analysis of variance of the curvilinear regression model for surface roughness.

\begin{tabular}{|c|c|c|c|c|c|}
\hline \multicolumn{6}{|c|}{$\begin{array}{c}\text { MRR }=-0.0871864+0.000221514 \text { on }+0.0119795 \mathrm{i}-1.09938 \mathrm{e}-006 \text { on } \times \text { on } \\
+3.08253 \mathrm{e}-007 \text { on } \times \text { off }+4.60924 \mathrm{e}-006 \mathrm{i} \times \text { on }-0.000300337 \mathrm{i} \times \mathrm{i}-8.08543 \mathrm{e}-006 \mathrm{i} \times \text { off }\end{array}$} \\
\hline Source & $\mathrm{DF}$ & Seq SS & MS & $\mathrm{F}$ & $\mathrm{p}$ \\
\hline regression & 8 & 57.1903 & 7.1488 & 49.1110 & 0.0000 \\
\hline I & 1 & 17.1320 & 1.6290 & 11.1911 & 0.0038 \\
\hline $\mathrm{T}_{\text {off }}$ & 1 & 1.8046 & 1.0997 & 7.5548 & 0.0137 \\
\hline $\mathrm{I} \times \mathrm{T}_{\text {on }}$ & 1 & 35.0044 & 5.7825 & 39.7250 & 0.0000 \\
\hline $\mathrm{T}_{\text {off }} \times \mathrm{T}_{\text {off }}$ & 1 & 0.4211 & 0.5647 & 4.8795 & 0.0454 \\
\hline $\mathrm{V} \times \mathrm{I}$ & 1 & 0.7611 & 0.9862 & 6.7752 & 0.0186 \\
\hline $\mathrm{V} \times \mathrm{T}_{\mathrm{off}}$ & 1 & 0.6777 & 0.6302 & 4.3294 & 0.0429 \\
\hline $\mathrm{T}_{\text {off }} \times \mathrm{T}_{\text {on }}$ & 1 & 0.4446 & 0.8019 & 5.5091 & 0.0313 \\
\hline $\mathrm{T}_{\text {on }} \times \mathrm{T}_{\text {on }}$ & 1 & 0.9449 & 0.9449 & 6.4914 & 0.0208 \\
\hline Error & 17 & 2.4746 & 0.1456 & & \\
\hline total & 25 & 59.6649 & & & \\
\hline $\mathrm{R}-\mathrm{sq}=95.79 \%$ & \multicolumn{2}{|c|}{$R-s q(\operatorname{adj})=94.16 \%$} & \multicolumn{3}{|c|}{ R-sq(pred $)=92.30 \%$} \\
\hline
\end{tabular}

- P-value: P-value confirms the suitability of this model. As can be seen, this value is less than $5 \%$ for the model coefficients, indicating the suitability of the residual coefficients in the model.

F-value: using statistical tables for the calculation of critical F-value, $\mathrm{F}_{0.05,8,17}$ is obtained 2.55 and $\mathrm{F}_{0.05,1,24}$ is equal to 4.26. According to the tables, $\mathrm{F}_{0}$ is more than critical values for the Curvilinear model and its coefficients. Hence, this value also confirms the suitability of the model and its coefficients. In the tables derived from the linear, Quadratic, and Logarithmic models, $\mathrm{P}$ and $\mathrm{F}$ values show that voltage and pulse off time have no effect on surface roughness.

- Residual plots: Figure 9 shows the residual plots for the Curvilinear model of surface roughness. Figure (A) shows the normal probability plot of residuals. According to what was discussed at the beginning of the section, this plot has an ideal state. Figure (B) also indicates that the residuals have been distributed randomly and do not follow any particular trend. Figure (C) shows the histogram of residuals that according to the bell-shape ideal form, symmetry of probability function around the average distribution, 
and its height, it can be said that the normal distribution is acceptable. Figure (D) also shows that all the standardized residuals are within a good range/interval.

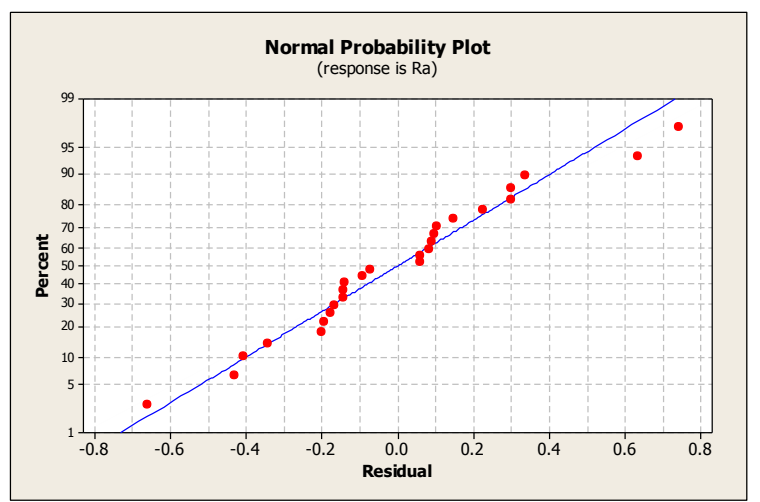

(A)

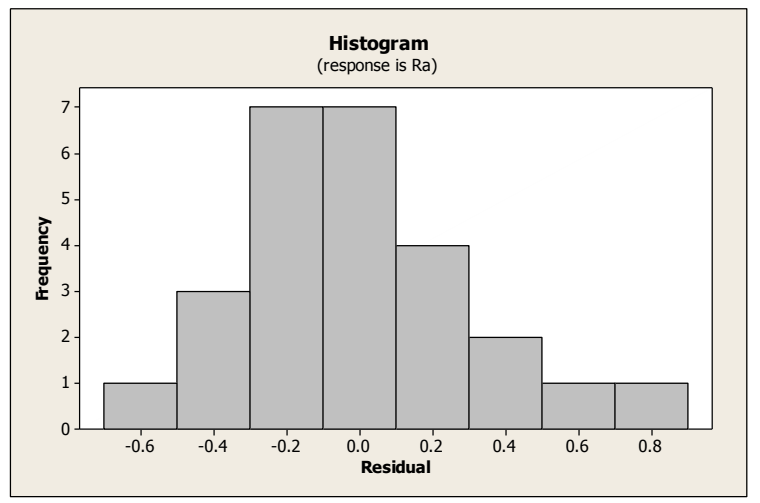

(C)

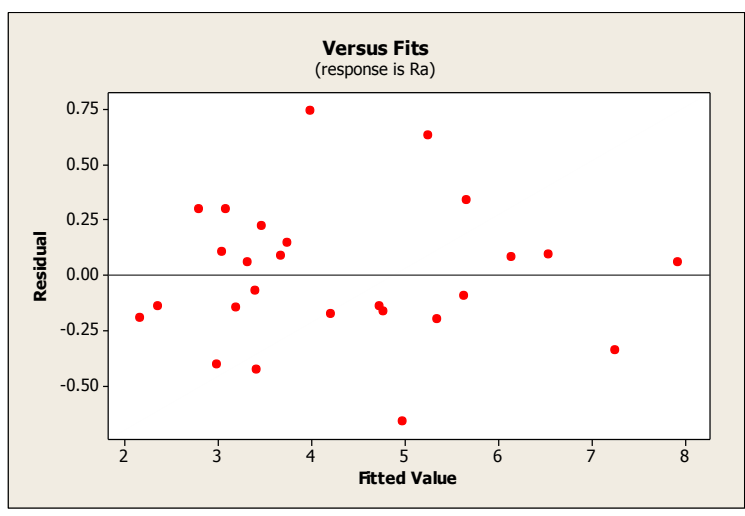

(B)

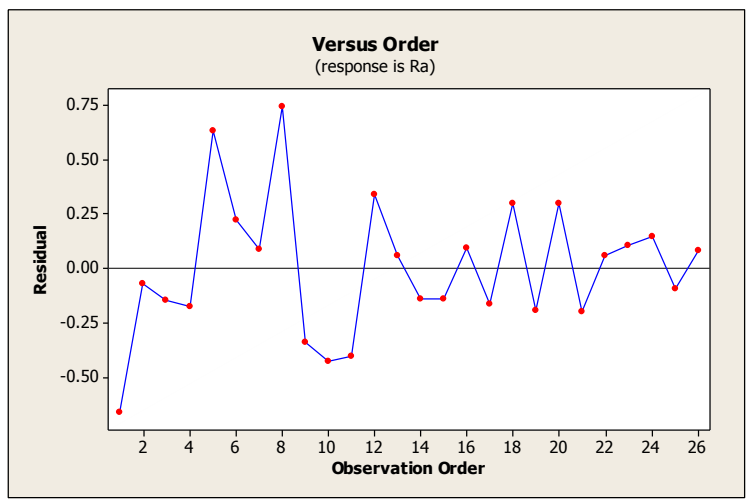

(D)

Figure 9: residual plots for the curvilinear model of surface roughness

- Optimization of surface roughness based on the best model: in order to find the optimal levels of surface roughness in electrical discharge machining, all the possible scenarios including 54 experiments have been investigated and the output of the model has been calculated for all of these scenarios. Since the aim is to minimize surface roughness, the lowest output belongs to the experiment where current intensity and pulse on time are set in their first levels and voltage and pulse off time in their second levels. Finally, in order validated the value predicted by the model, an experiment was conducted with new levels and the model output was compared with the actual output. The results are shown in Table 16.

Table 16: Optimization of surface roughness

\begin{tabular}{lccc}
\hline Optimal levels & Experimental value & Predicted value & error \% \\
\hline $\mathrm{V}_{2} \mathrm{I}_{1} \mathrm{~T}_{\text {on1 } 1} \mathrm{~T}_{\text {off } 2}$ & 2.159 & 2.355 & 8.323 \\
\hline
\end{tabular}

As can be seen, the prediction error is about $8 \%$. This error is due to the effect of environmental factors and other uncontrollable parameters on the machining process. Given the uncertainties of electrical discharge machining and its industrial nature, this amount of prediction error is acceptable that verified by Rajmohan and Prubho (2012). The comparison plots of the experimental results and the prediction results of the regression model for the output of surface roughness are as follows (See Figure 10): 

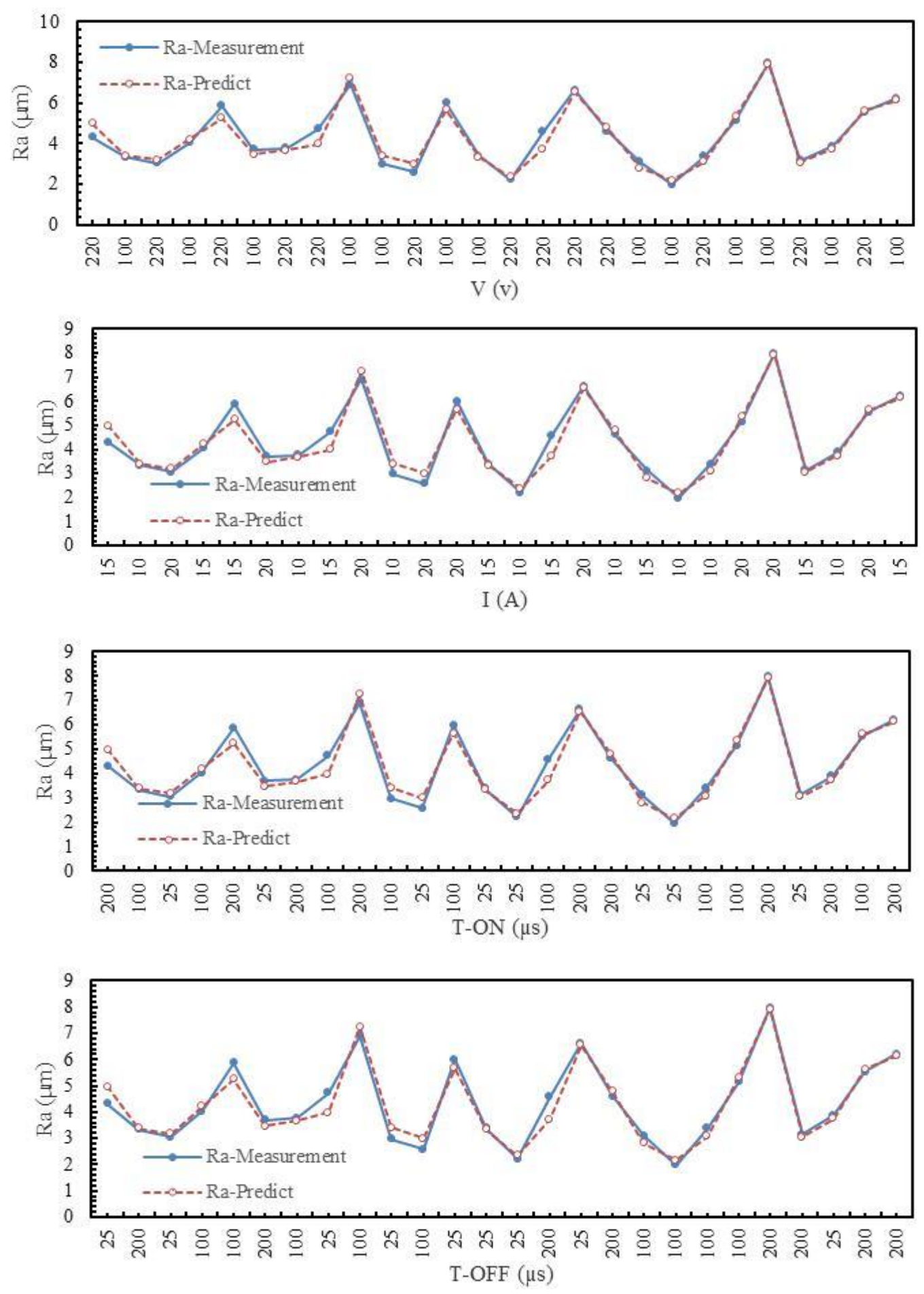

Figure 10: Comparison plots of the experimental results and the prediction results of the regression model for the output of surface roughness

\section{Conclusion}

Similar results are provided by the statistical analysis conducted in both models. In the investigation of material removal rate it was found out that to have the maximum material removal rate, voltage and pulse on time should be in their highest level but pulse off time should be set in its lowest level. Doing this, the maximum discharge energy is produced and material removal rate increases. Voltage has no effect on this output parameter; but, the parameter of current intensity, with the highest percentage of impact, is the most important 
setting parameter. Then, pulse on time and pulse off time are the most influential parameters respectively. Furthermore, in the investigation of surface roughness, it was observed that the parameter of voltage has no effect on this output. Similarly, pulse off time also has no significant effect on surface roughness, while current intensity and pulse on time have the highest impact respectively. This is due to the fact that the reduction of them decreases the discharge energy and lowers material removal power of the spark and, hence, surface roughness is reduced. In reviewing the results of the validation experiments, as was observed, both models have an appropriate precision.

Finally, it can be said that working voltage has no essential role in material removal rate and, thereby, in surface roughness and only causes ionization process to be performed with the desired speed. Little difference between material removal rate and surface roughness at two levels of voltage parameter together with $\mathrm{P}$ and $\mathrm{F}$ values of different tables is confirming. The change of current in spark is linear and has the outmost impact on the two output parameters. The higher the amount of current, the more will be material removal rate and, hence, surface roughness decreases. Increased current intensity causes the creation of maximum discharge energy rate on the surface of workpiece and, through melting and vaporizing larger quantities of the workpiece, increases MRR. The high impact of current intensity on surface quality is due to the fact that the decreased current intensity reduces the spark energy severely and, thus, much smaller amount of workpiece surface is melted and vaporized. Therefore, the depth of surface cavities is reduced which means reduced surface roughness. With regard to pulse on time and off time, as described in previous sections, pulse on time determines the creation time and real presence of spark between the workpiece and electrode. By increasing this parameter, a larger amount of the work surface is removed in each cycle and, thus, we will have more material removal rate and lower surface roughness. Indeed, the unusual reduction of on-time or the mismatch between on-time and current leads to severe corrosion of the electrode, prolonged work, and undesirable quality. In off-times, the current is cut off and the particles exfoliated from the metal surface are removed from the place by using dielectric fluid. The less the off channel, the more will be the average number of sparks per unit of time and, hence, the speed of material removal rate increases; this is suggested by MRR-related results. However, with regard to surface roughness, because of the ineffectiveness of this parameter, different surfaces were determined. It should be noted that the mismatch between on-time and off-time leads to severe increase and decrease of pule off time, resulting in dielectric breakdown, arch creation and graphite formation. Moreover, high voltage, after an optimal level, increases the clearance gap which in turn decreases the depth of surface melting and material removal rate. The two considered outputs are essentially different; this means that the decreased surface roughness (increased surface quality) is equivalent to the reduced material removal rate and vice versa.

Finally, it was determined that both models/designs have an appropriate precision; however, regression modeling through using the optimal matrix data is more precise that is due to two reasons: first, the number of experiments in this design is more than Taguchi design and, second, this design considers the interaction between the parameters. This is while that in Taguchi design the effect of each parameter is analyzed separately.

\section{References}

Ayesta, I., Izquierdo, B., Sánchez, J. A., Ramos, J. M., Plaza, S., Pombo, I and Zamakona, I. (2013): Influence of EDM parameters on slot machining in C1023 aeronautical alloy, Procedia CIRP, 6, 129-134. https://doi.org/10.1016/j.procir.2013.03.059

Clijsters, S., Liu, K., Reynaerts, D. and Lauwers, B. (2010): EDM technology and strategy development for the manufacturing of complex parts in SiSiC, Journal of Materials Processing Technology, 210(4), 631-641. https://doi.org/10.1016/j.jmatprotec.2009.11.012

Dave, H. K., Desai, K. P. and Raval, H. K. (2012): Modelling and analysis of material removal rate during electro discharge machining of Inconel 718 under orbital tool movement, International Journal of Manufacturing Systems, 2(1), 12-20. https://doi.org/10.3923/ijmsaj.2012.12.20

Esfe, M. H., Afrand, M., Gharehkhani, S., Rostamian, H., Toghraie, D. and Dahari, M. (2016): An experimental study on viscosity of alumina-engine oil: effects of temperature and nanoparticles concentration, International $\begin{array}{llll}\text { Communications in } & \text { Heat and } & \text { Mass } 208 .\end{array}$ https://doi.org/10.1016/j.icheatmasstransfer.2016.05.013

Gopalakannan, S., Senthilvelan, T. and Ranganathan, S. (2012): Modeling and optimization of EDM process parameters on machining of Al 7075-B4C MMC using RSM, Procedia Engineering, 38, 685-690. https://doi.org/10.1016/j.proeng.2012.06.086 
Hashemzadeh, H., Eftekhari, S. A. and Mousavi, M. L. (2017): Forging pre-form dies optimization using artificial neural networks and continuous genetic algorithm, An International Peer Reviewed Open Access Journal For Rapid Publication, 74.

https://doi.org/10.1016/j.jmatprotec.2006.11.202

Jafari, D. M., Kolahdooz A. and Eftekhari S. A. (2016): Investigation of notching HSS rolls with high hardness for hot mill rolling, Journal of Mechanical Engineering and Vibration, 7(2), 7-14.

Kalpakjian, S. and Schmid, S. R. (2014): Manufacturing engineering and Technology (p. 913), K. V. Sekar (Ed.), Upper Saddle River, NJ, USA: Pearson.

Kolahdooz, A., Nourouzi, S., Jooybari, M. B. and Hosseinipour, S. J. (2014): Experimental investigation of thixoforging parameters effects on the microstructure and mechanical properties of the helical gearbox cap, Journal of Mechanical Science and Technology, 28(10), 4257. https://doi.org/10.1007/s12206-014-0939-Z

Manikandan, R. and Venkatesan, R. (2012): Optimizing the machining parameters of micro-EDM for Inconel 718. Journal of Applied Sciences(Faisalabad), 12(10), 971-977. https://doi.org/10.3923/jas.2012.971.977

Mirkalantari, S. A., Hashemian, M., Eftekhari, S. A. and Toghraie, D. (2017): Pull-in Instability Analysis of Rectangular Nanoplate based on Strain Gradient Theory Considering Surface Stress Effects, Physica B: Condensed Matter, 519, 1-14. https://doi.org/10.1016/j.physb.2017.05.028

Nourouzi, S., Kolahdooz, A. and Botkan, M. (2012): Behavior of A356 Alloy in semi-solid state produced by mechanical stirring, Advanced Materials Research (Vol. 402, pp. 331-336): Trans Tech Publications.

Rajmohan, T., Prabhu, R., Rao, G. S. and Palanikumar, K. (2012): Optimization of machining parameters in electrical discharge machining (EDM) of 304 stainless steel, Procedia Engineering, 38, 1030-1036. https://doi.org/10.1016/j.proeng.2012.06.129

Rajmohan, T., Prabhu, R., Rao, G. S. and Palanikumar, K. (2012): Optimization of machining parameters in electrical discharge machining (EDM) of 304 stainless steel, Procedia Engineering, 38, 1030-1036. https://doi.org/10.1016/j.proeng.2012.06.129

Semiromi, D. T. and Azimian, A. R. (2011): Molecular dynamics simulation of nonodroplets with the modified Lennard-Jones potential function, Heat and Mass Transfer, 47(5), 579-588. https://doi.org/10.1007/s00231-0100747-7.

Taguchi, G., Chowdhury, S. and Wu, Y. (2005): Taguchi's quality engineering handbook, Wiley.

Tzeng, Y. F. (2008): Development of a flexible high-speed EDM technology with geometrical transform optimization, Journal of materials processing technology, 203(1), 355-364. https://doi.org/10.1016/j.jmatprotec.2007.10.034

Tzeng, Y. F. and Chen, F. C. (2007): Multi-objective optimisation of high-speed electrical discharge machining process using a Taguchi fuzzy-based approach, Materials and Design, 28(4), 1159-1168. https://doi.org/10.1016/j.matdes.2006.01.028

Uhlmann, E. and Domingos, D. C. (2013): Development and optimization of the die-sinking EDM-technology for machining the nickel-based alloy MAR-M247 for turbine components, Procedia CIRP, 6, 180-185. https://doi.org/10.1016/j.procir.2013.03.102

Vishwakarma, M., Parashar, V. and Khare, V. K. (2012): Regression analysis and optimization of material removal rate on electric discharge machine for EN-19 alloy steel, International Journal of Scientific and Research Publications, 24(11), 35-46.

Yazdi, M., Latifi Rostami, S. and Kolahdooz, A. (2016): Optimization of geometrical parameters in a specific composite lattice structure using neural networks and ABC algorithm, Journal of Mechanical Science and Technology, 30(4). https://doi.org/10.1007/s12206-016-0332-1

Zarepour, H., Tehrani, A. F., Karimi, D. and Amini, S. (2007): Statistical analysis on electrode wear in EDM of tool steel DIN 1.2714 used in forging dies, Journal of Materials Processing Technology, 187, 711-714.

Zarringhalam, M., Karimipour, A. and Toghraie, D. (2016): Experimental study of the effect of solid volume fraction and Reynolds number on heat transfer coefficient and pressure drop of $\mathrm{CuO}-$ water nanofluid, Experimental Thermal and Fluid Science, 76, 342-351. https://doi.org/10.1016/j.expthermflusci.2016.03.026 